\title{
Male patients' gender preferences for hospital nurses
}

\author{
Mitchell LeBlanc ${ }^{1}$, Janet Bryanton*1, Kim Wood ${ }^{2}$ \\ ${ }^{1}$ Faculty of Nursing, University of Prince Edward Island, Charlottetown, PE, Canada \\ ${ }^{2}$ Unit 8, Queen Elizabeth Hospital, Charlottetown, PE, Canada
}

Received: May 6, 2019

DOI: $10.5430 /$ jnep.v9n9p115

\author{
Accepted: June 20, 2019 \\ Online Published: June 25, 2019 \\ URL: https://doi.org/10.5430/jnep.v9n9p115
}

\begin{abstract}
There has been limited research exploring the beliefs and attitudes of male patients regarding the gender of their nurses. These attitudes, as well as the factors affecting the gender-preference of male patients, must be explored in a flexible, holistic manner. The objective of our study was to explore key aspects of male patients' beliefs and attitudes about the gender of their nurses in the hospital setting, as well as the factors that influenced those perceptions. We employed a descriptive, qualitative, cross-sectional design. Data were collected through one-on-one interviews, which were transcribed verbatim. A deductive and inductive approach using content analysis of each question was used to analyse the data. Ten male patients were interviewed. Initially, participants reported no gender preference for their nurses. The majority agreed that the nature of the task did not matter in their preference for a male or female nurse. Most suggested that females were inherently better suited to nursing than males due to their ability to be caring, nurturing, and detail-oriented. Bussey and Bandura's Social Cognitive Theory of Gender Development and Differentiation was supported and provided a suitable framework for the study. There is a need for educational institutions to determine new ways to teach male nursing students to be caring, nurturing, and detail-oriented. Whether nurses are male or female, having a caring approach is important to patients, as well as possessing other 'ideal' characteristics.
\end{abstract}

Key Words: Male patient, Male nurse, Gender preference, Attitude, Beliefs

\section{INTRODUCTION}

Traditionally, the nursing profession has been perceived primarily as a female profession. ${ }^{[1]}$ However, in the past decade, the number of male nurses has almost doubled and now is about $8 \%$ of all nurses in Canada. ${ }^{[2]}$ With an increase in the number of male nurses, one might question, do patients have a preference regarding the gender of their nurses? Having evidence of the beliefs and attitudes of patients regarding the gender of their nurses can be invaluable in enabling nurses to perform care that preserves dignity, as well as being safe, compassionate, competent, and ethical. ${ }^{[3]}$

Several studies have investigated patients' preferences regarding the gender of health care professionals, ${ }^{[4,5]}$ particularly female patients in the areas of obstetrics, gynecology, and general practice. ${ }^{[4-6]}$ However, there is limited research that focuses on the profession of nursing ${ }^{[6-9]}$ and even less that examines the gender preferences of male patients related to their nurses. ${ }^{[7-9]}$ No studies were found that focused solely on beliefs and attitudes of male patients regarding the gender of their nurses.

The literature suggests that for more 'technical' cares (e.g., having vital signs taken), patients do not seem to have a significant gender preference. ${ }^{[9]}$ For 'intimate' cares (e.g., bathing), both male and female patients appear to have a same-gender preference, with women showing a stronger preference than men. ${ }^{[5,8,9]}$ In contrast, a current Jamaican

\footnotetext{
*Correspondence: Janet Bryanton; Email: jbryanton@upei.ca; Address: Faculty of Nursing, University of Prince Edward Island, Charlottetown, PE,
} Canada. 
study found that $80 \%$ of male patients would not allow a male nurse to give them an enema. ${ }^{[7]}$ It is not fully known if factors such as age, lack of exposure to male nurses, or culture influence how strongly a patient's feelings are regarding gender preference. ${ }^{[6,7,9]}$

Research has shown that often pre-existing attitudes about gender within nursing have influenced the reasons behind gender preference. ${ }^{[6,9,10]}$ There has been a widespread stereotypical attitude within nursing that males are not suitable for the profession. ${ }^{[1]}$ Even Florence Nightingale, the matriarch of nursing, believed that men were detrimental to caring. ${ }^{\text {[11] }}$ This attitude may influence the patient's perception that nursing is a female profession. ${ }^{[10]}$ Over the past two decades, some attitudes have begun to change, with more rejection of the stereotype of nursing as a female profession. ${ }^{[9]}$ Even so, many patients still believe that nursing should be a primarily female profession and that males do not possess the necessary empathy and caring skills to be a nurse. ${ }^{[10]}$

Research related to male patients' preferences regarding the gender of their nurse has been quantitative, with no qualitative studies identified. ${ }^{[5,7-9]}$ These studies lack the depth that qualitative research designs allow. ${ }^{[12]}$ Qualitative research is needed to provide a holistic picture of male patients' gender attitudes and beliefs.

In summary, there has been limited research exploring the beliefs and attitudes of male patients regarding the gender of their nurses. Most research about gender preference has focused on females and has not addressed nursing. Although quantitative research has shed some light about why patients prefer a specific gender, studies have not done an adequate job of answering why certain preferences exist. The culture of nursing, as well as how it is seen by patients, appears to have been influenced by pre-existing attitudes regarding gender. These attitudes, as well as the factors affecting the gender-preference of male patients must be explored in a flexible, holistic manner. Therefore, the purpose of this study was to explore key aspects of male patients' beliefs and attitudes about the gender of their nurses in the hospital setting, as well as the factors that influenced those perceptions. The research questions were the following: 1) What are the beliefs and attitudes of male patients about the gender of their nurses in the hospital setting? 2) What are the factors that influence these perceptions?

\section{Theoretical framework}

The theoretical framework used to guide this study was Bussey and Bandura's Social Cognitive Theory of Gender Development and Differentiation. ${ }^{[13]}$ This theory was used as an organizing framework for our study and was the lens through which the interviews and data analyses were conducted. It hypothesizes that gender-linked roles and conduct, as well as preconceived notions of gender and gender development, are influenced by three main factors: modeling, enactive experience, and direct tuition. The authors' interpretation of this model is shown in Figure 1.

Modeling is conceptualized as one of the most pervasive and powerful means of transmitting values, attitudes, and patterns of thought and behavior. ${ }^{[14]}$ It is not simply mimicry, but a way to convey the rules and structures of generative behavior in a higher level of learning defined as abstract modeling. This learning, rather than mimicry, leads to the generation of new patterns of behavior that abide by these rules and structures, but advance beyond what they have been taught. It is hypothesized that modeling allows a great deal of gender-linked information to be transferred by models in one's immediate environment, as well as through the media and significant persons in social, educational, and occupational contexts. ${ }^{[13]}$

Enactive experience is conceptualized as the judgement of gender linkage of conduct from the results of one's actions. Conceptions of gender orientations can be developed and refined based on the observation of the positive and negative consequences of differing patterns of behavior. ${ }^{[13]}$

Direct tuition is conceptualized as teaching by persons in one's social environment. However, should the teacher (model) providing the direct tuition contradict what is taught (not practicing what he/she preaches), then the tuition's impact is weakened. ${ }^{[15]}$ The influence of tuition is most effective when it is based on shared values between the teacher and the student, as well as when it receives widespread social support. ${ }^{[13]}$ Bussey and Bandura ${ }^{[13]}$ hypothesize that direct tuition serves as a convenient way of informing people about varying styles of conduct and their linkage to gender. It is also often used to generalize the informativeness of certain behavioral outcome experiences.

Gender-linked behavior is heavily socially sanctioned in our society, and because of this, social reactions are important sources of information for constructing gender conceptions. ${ }^{[13]}$ Social sanctions are conceptualized as genderlinked outcomes that are socially prescribed rather than internally motivated. They are regulators of gender conduct and role behavior and are motivated by social consequences such as approval and praise/reward for activities that are considered appropriate gender-linked behavior. They can also be motivated by consequences such as disapproval or punishment for behavior considered inappropriate gender-linked behavior. ${ }^{[13]}$ Social sanctions may lead to self-sanctions, which are defined as a shift from external social sanctions 
to self-sanction that is directed by individualized standards, influencing male patients' perceptions regarding the gender due to the development of self-reactive capabilities. ${ }^{[13]}$ In of their nurses were explored. this study, the influences of modeling, enactive experience, direct tuition, social sanctions, and self-sanctions as factors

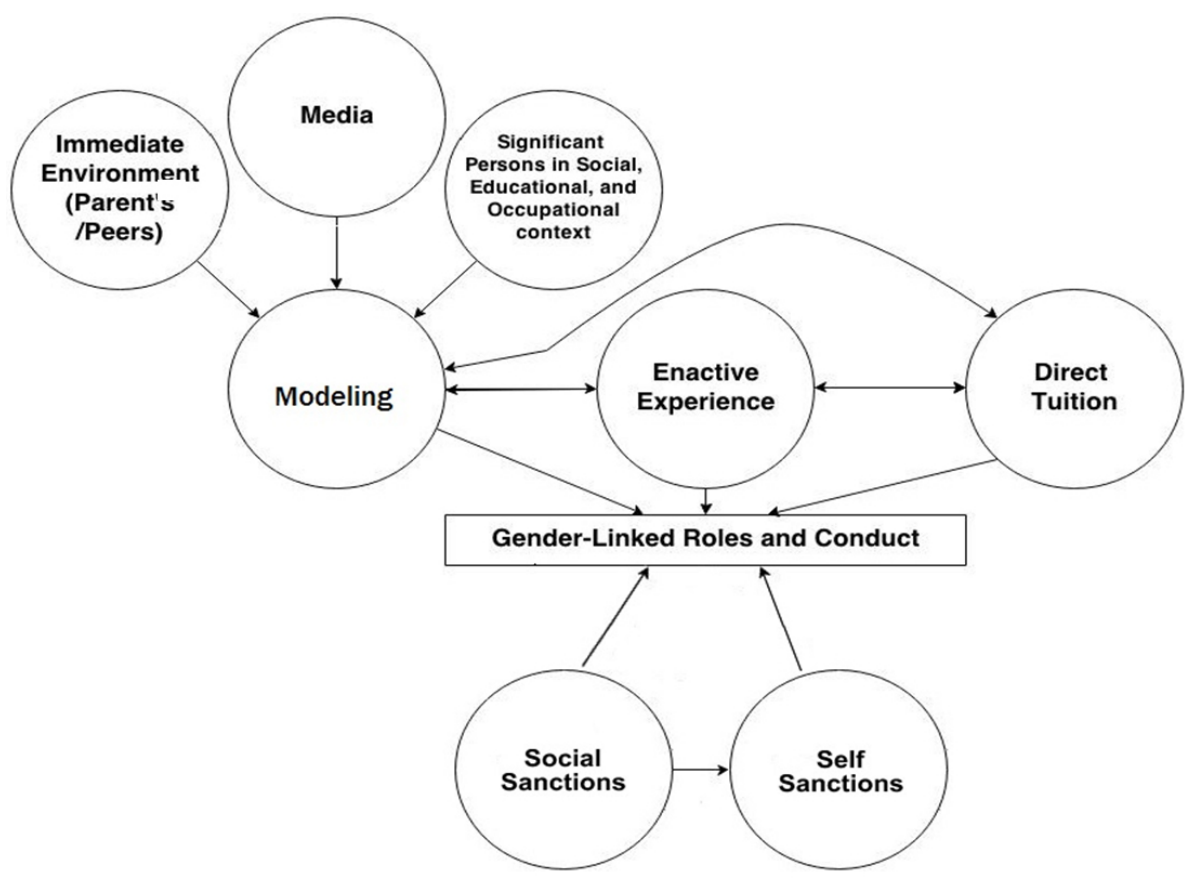

Figure 1. Authors' Interpretation of Bussey and Bandura's (1999) Model ${ }^{[13]}$

\section{METHODS}

\subsection{Design/setting}

The study employed a descriptive, qualitative, cross-sectional design. The in-hospital recruitment and data collection were conducted on a 40-bed medical unit (30 beds general medical and 10-bed stroke unit) of a general hospital in Eastern Canada.

\subsection{Sample/recruitment}

Following ethics approval by the university and hospital research ethics committees, a convenience sample of 10 patients was recruited. The participants were required to be male patients, $\geq 18$ years of age, and in stable physical and psychological condition. They also needed to be able to read and speak English and be mentally capable of providing consent. The third author identified eligible patients on her unit by reviewing the nursing kardex on a regular basis.

Once eligible participants were identified, the third author gave them a letter of information or read it to them, depending on their wishes. This was done in their room with the curtains drawn. If they were interested in taking part, written consent was obtained.

\subsection{Data collection}

Data were collected via semi-structured interviews, which lasted up to 30 minutes. Participants were encouraged to share their attitudes and beliefs regarding gender preference related to nurses and were given the freedom to expand upon what they believed was important to them. Interviews were conducted by the first author in a private location on the unit, if the patient was able to ambulate or be transported there and wished to do so, or at the patient's bedside with the curtains drawn if the patient chose and consented to doing so. The interviews were tape recorded with participant consent. A series of nine questions were asked to each participant, with appropriate probing as required. Demographic data were also collected. We continued to conduct interviews until data saturation was reached at 10 interviews. To protect patient confidentiality, transcribed interviews and demographic data collection forms were coded and no names were attached. Patients were asked for permission to use quotations. To further protect anonymity, pseudonyms were used, and we were careful not to use quotes that might identify an individual. Participants were made aware of the voluntary nature of the study and their right to withdraw or not answer certain questions without their care being affected. At the end of the interview, participants were encouraged to ask questions as 
a form of debriefing. They were also sent a plain language summary of the results, if they requested it. Participants had the right to withdraw their data up to the time of publication. Patient confidentiality was also maintained by the study team during and after the conduct of the study. Consents, demographic forms, code sheets, tape recorder, and transcribed interviews were kept in a locked drawer on the unit during the study. Study materials are being housed in a locked filing cabinet at the university for 5 years and then will be destroyed.

\subsection{Data analyses}

A deductive and inductive approach was used to analyse the data. ${ }^{[16]}$ Each interview was transcribed verbatim, read in its entirety, and then analysed question by question using content analysis. Initially free and open coding was done for each question. Then the theoretical framework was used as a lens for the development of codes, which were collapsed into categories corresponding to the five main categories and sub-categories of the framework. Lastly, codes and themes that did not fit with the framework were extracted from the data inductively. To enhance study trustworthiness, the first two authors analyzed all interviews independently and came to a consensus on the categories and themes. An independent rater also assisted with inter-rater reliability, which was completed for two interviews with an $80 \%$ inter-rater agreement.

\section{RESULTS}

\subsection{Participants}

The 10 participants ranged in age from 59 to 83 years, with a mean age of 72 years. Their education level ranged from Grade 8 to a completed university degree, and they were diagnosed with a variety of acute and chronic medical conditions. All but one participant reported having had experiences being cared for by male nurses in either current or previous hospitalizations.

\subsection{Beliefs and attitudes about gender preferences}

When first asked questions, the participants often gave a "yes" or "no" answer and when they elaborated, they frequently contradicted their initial response. Most participants initially reported that the gender of their nurse did not matter to them. One man reported that he preferred female nurses to male nurses, and another reported having no preference, but then later discussed preferring female nurses to males.

Most participants did not believe that the nature of the task being done by the nurse affected their preference for a female or male nurse. One man stated, however, that he would prefer a female nurse for more intimate cares. When asked for the reasons behind this preference, Harold stated: "I don't know what the reasoning is behind that-because-the same as your mother giving you your bath, like I say it all stems back to your childhood." Another man commented that he would be more comfortable with a male nurse assisting him with more intimate cares.

When asked about the ways females and males interact with them when providing care, most participants believed that there was no difference. Leonard stated: "Well I think they pretty much act the same... you get good service no matter what." Participants who believed that there was a difference, reported that female nurses were more caring and nurturing than males. Bradley reported: “... the female nurses seem more caring, you know... they just seem more personable and more caring, but it's in their attitude or their way . . .. Another participant identified females as being better communicators. Shawn said: "I find a female got a little better way of putting it across." One participant identified females as being more competent and detail-oriented than males. Harold commented:

I find that I prefer females because they tend to not only tend to your care, but also to your mental state of being too, where males, it's more let's get this done and I'm out of here kind of thing, and on to the next patient..... Like I said a male can do. He'll put a bandage on the same way as a female would but only, he'll slap it on where a female will make sure it's perfect, you know?

When directly asked if they believed that one gender was better suited to nursing, most participants reported that they did not think that one gender was better suited to nursing. However, most of those men later reported that they thought that females were better suited to nursing than males. The theme of 'Nursing Attributes' arose inductively from the data with two subthemes: 'Differences in Caring' and 'Ideal Characteristics'. These sub-themes were interwoven with the deductive themes arising from the theory.

As noted, some participants suggested that female nurses appear more caring than male nurses. Bradley commented, "Really, I guess I would have to lean towards the female side, and I'd have to, although I have no problem with the males, but-but a female gives you the impression anyway, that they're more caring than the male." Steve discussed caring in the following statement:

I think it's probably emotional support or it's probably easier for females to deliver, because that's what they've been taught and that's howthat's how they relate to their children and all 
that sort of thing, but I think men are traditionally... have to be stronger, more silent and not to show emotion and whatnot, but I think, like I said before, I think it's the same thing only a different package, and it probably comes easier to a female.

The second subtheme that arose from the data was that nurses should possess 'Ideal Characteristics', and this was a very important factor in determining whether they would like that nurse to take care of them, not the gender. For example, Steve commented:

Well, I think people who go into nursing do it for the right reasons, and if they aren't doing it for the right reasons, then they don't continue on, and I think if somebody, not very many people go into nursing just for the paycheck...

Bradley stated:

... if this is your life profession, stick with it and good luck and you know, I hope you enjoy it, and I also feel that-that it does take a certain type of person to do that job whether it be male or female, you know, I-it's something that I don't think everybody is capable of doing, you know I think you have to be dedicated and-and-and well there's a lot of people that probably would never make it. It's-it's the caring that-that I see that, you know, that gives you a good feeling, you know...

\subsection{Factors influencing perceptions}

Several factors were identified by participants as influencing their perceptions about the gender of their nurses. The main categories of factors that arose deductively from the framework included: enactive experience, modeling, direct tuition, social sanctions, and self-sanctions.

\subsubsection{Enactive experience}

When asked if there was any person or thing in their life that influenced their ideas about the gender of their nurses, all participants but one reported no direct influence on their beliefs. However, during the interviews, it became clear that there were influences. Participants frequently described enactive experiences with male nurses during their current or previous hospitalizations. For example, Larry stated:

I remember the first time I got one, like it was probably 3 years ago, a male fella, he was a man probably in his early 50 s or something. But I thought he was the greatest nurse, like he was really so dedicated.... Steve also commented: Published by Sciedu Press
... I've had male nurses in (city) and (city) and (city) and I don't know. The gender questions that were on my mind have gone away. It just-it just doesn't matter, you know. People always, most often surprise you, that's one of the joys of life; that you see the sides of people that-I don't know where to go from there, but it just-it just doesn't matter anymore.

Regis remarked: “...I guess it's the experience of being a patient frequently has influenced me the most." Shawn, who had previously reported not having very many experiences with male nurses, identified a lack of enactive experiences with male nurses affecting his preference. He said, "I'd have to have the experience both ways over a period of time and take it from there."

\subsubsection{Modeling}

The concept of modeling from the immediate environment was also mentioned throughout several of the interviews. The men reported modeling from their parents, a grandmother, and a spouse. For instance, Bradley expressed:

... Fathers today are more tender and caring, and you know, there's lots of fathers that are looking after the children, but-geeze, in my day, you know, that wasn't a thing at all. You know, you went with your father for this and that and the other thing, but your father certainly wasn't as caring as your mother...

Harold commented, “... The same as your mother giving you your bath, like I say it all stems back to your childhood." Modeling from the media and significant persons in the social, educational, and occupational context may have had an influence on participants but this was not explicitly identified.

\subsubsection{Direct tuition}

Only one participant described an example of direct tuition influencing his thoughts and beliefs. Steve stated: "When I went back to university, I learned the term 'maternal feminism' and read some papers about how society expects women to be nurses and teachers and men to be welders and engineers...".

\subsubsection{Social sanctions}

Several participants mentioned instances of social sanctions that influenced them. Regis said:

... Sometimes as a patient you don't always notice the ID of someone on a ward; you rightly or wrongly assume that a female who is not a doctor is a nurse, but not always that same presumption with a male. 
Steve commented on the easiness of stereotyping careers by their traditional gender roles: “. . . you know it's easy to put tags on people and say all physiotherapists are female and all occupational therapists are female and or people who do orthotics are male ....'.

\subsubsection{Self-sanctions}

The men also described self-sanctions as influencing their gender-linked thoughts and behaviors more frequently than social sanctions. One example of this was when Bradley commented:

... Just because, say my father or my grandfather, there's no damn way that he'd let a female nurse do anything with him, you know? But you can't take that attitude today; you've got to go with it, with that's the current practice. ...

\subsection{Change over time}

Another important theme that arose inductively from the data was that of 'Change Over Time'. A slight majority of participants reported that they have always held their current gender preferences towards nurses. However, several reported changes in their attitudes regarding male nurses over time. For example, Steve reported:

... One of the thoughts that came into my headwhat was the gender preference? Was this a gay person? That's the very early thoughts on the matter but since I've met so many male nurses who have been deep-sea fisherman and one of my nurses is-played junior hockey. I still don't know what his gender preference is, but it really doesn't matter.

Enactive experiences with nurses of both genders were the primary catalyst for changes in gender preferences of participants. Steve reported changing his preferences:

... They've just gone away because I've had so many nurses, male nurses who engaged in-in profession-had hobbies like drag-racing cars or deep-sea fishing for tuna or work the lobster boats and-and did stuff like that, so it's become a non-starter. I firmly believe in respecting whoever works with me.

Steve also identified direct tuition from his children as a key factor in changing his original preference towards nurses. $\mathrm{He}$ remarked:

I strongly thought that you know; male nurses are probably gay. But as I've been educated by my children and one of my daughters you knowI believe we help each other in this life and she was definitely of a feminist bent and she tells me not to call women girls and not to call girls ladies, to refer to people as people, you know.

Frequently, self-sanctions were often influenced by a personal change over time, as well as a realization of societal, health system, and professional changes. For instance, Bradley stated:

As you go through life, your attitude will change on a number of things, really. And it's probably just a process of growing up or aging, and then you know, times have changed too, you know, your surroundings have changed...

\section{Discussion}

To our knowledge, this is the first qualitative study addressing male patients' perceptions related to the gender of their nurses and the factors that influence these beliefs and attitudes. The qualitative nature of this study allowed for their perspectives to be explored in greater depth, from a holistic viewpoint. It adds to the limited body of knowledge which focuses on nursing and includes male patients. ${ }^{[7-9]}$

When initially asked, participants reported that they did not have a gender preference in their nurses. This appeared to be less clear as the interviews progressed. Although somewhat mixed, the majority agreed that the nature of the task did not matter in their preference for a male or female nurse. This is consistent with research by Chur-Hansen, ${ }^{[9]}$ which found that for more 'technical' cares, patients do not seem to have a significant gender preference for male or female nurses; however, it differs from Kerssens et al's ${ }^{[5]}$ and Chur-Hansen's ${ }^{[9]}$ studies that reported, for 'intimate' cares, both male and female patients appear to have a same-gender preference, with women showing a stronger preference than men. ${ }^{[5]}$ It also differs from a recent study that found the majority of male patients would not allow a male nurse to give them an enema. ${ }^{[7]}$ It is possible that the differences are culturally based or influenced by age.

Most men answered that there were no differences in the way male and female nurses interacted with them, and when initially asked, the majority stated that one gender was not better suited to nursing than the other. However, when further questioned, an important sub-theme immerged. A majority of the male patients suggested that females were inherently better suited to nursing than males. They reported that female nurses are more caring, nurturing, and detail-oriented than their male counterparts. These findings concur with previous 
research, which found that $45 \%$ of male patients surveyed believed that female nurses were more thoughtful and better able to boost patient morale than males. ${ }^{[8]}$ In a study of male nursing students, Tollison ${ }^{[1]}$ found that students were more tentative when they were involved in a simulation with a male patient that involved being empathetic. The author suggested that expressing empathy may serve as a threat to their masculinity. Cudé and Winfrey ${ }^{[10]}$ reported that males find the process of learning to care awkward.

In accordance with previous research, ${ }^{[6,9]}$ our study affirmed that pre-existing attitudes about gender within nursing influence gender preferences. The results support Bussey and Bandura's Social Cognitive Theory of Gender Development and Differentiation ${ }^{[13]}$ by showing that each of the factors operate in complex ways. It highlighted the influence that factors such as enactive experiences, modeling, direct tuition, social sanctions, and self-sanctions, have on the gender preferences of male patients. ${ }^{[13]}$

The results showed that most participants believed that they were not influenced by mass media. It is important to note that participants may not have been consciously aware of more subtle influences on their attitudes or perceptions. Mass media has been shown to dispense examples of modeling of both gender roles and conduct on a subtle and even subliminal level. ${ }^{[13]}$

This study has also identified the importance of personal change over time, as well as societal, system, and professional changes and how these influence changes in perceptions. In particular, the results highlighted the importance of enactive experiences in changing pre-conceived gender preferences of male patients. ${ }^{[13]}$ It is also important to realize that the impact of each of these factors will change depending on the developmental status of individuals, as well as the social structuring of experiences. Due to this, certain factors may be influential depending on the period of development. Modeling is considered to have a strong influence from birth, and direct tuition increases in influence as children develop language skills. Enactive experience, as well as social sanctions, develop throughout life, and self-sanctions normally develop following previous social sanctions. ${ }^{[13]}$

Lastly, one important sub-theme arose from the data which suggested that having 'ideal characteristics' such as: 'doing' it for the right reason not the pay cheque, being competent, enjoying nursing, and being dedicated are very important no matter whether the nurse is male or female. This is an important consideration that requires further investigation.

Published by Sciedu Press

\subsection{Limitations}

The interviewer was a male student nurse, and this could have possibly influenced the responses of participants. In future studies, giving participants the option to have a female interviewer could possibly allow for a greater comfort level for participants. The lack of younger participants may limit the transferability of the results. Chur-Hansen ${ }^{[9]}$ found that older patients tended to have less gender preferences for their nurses. The $80 \%$ inter-rater reliability, although acceptable, may have been affected by the complex interplay between the categories in Bussey and Bandura's model. ${ }^{[13]}$

\subsection{Implications for practice, education, and research}

This study has implications for practice, education, and research. It identifies possible barriers for practicing male nurses, such as a perceived lack of caring, as well as a lack of attention to detail. The study also provides feedback for male nurses regarding what male patients are looking for in their nurse. 'Ideal' characteristics such as being in nursing for the right reason, being competent, enjoying nursing, and being dedicated are important for all nurses to demonstrate. The results suggest that educational institutions should educate all student nurses about the importance of these ideal characteristics and of being 'caring' in their approach. In particular, they need to focus on assisting male students to acquire the skills to demonstrate 'caring' with patients, as well as being nurturing and detail-oriented. Further research should focus on the differences in caring and nurturing between male and female nurses, as well as the relationship between male patients and those who take care of them. Additionally, more research is required to determine whether age influences patients' gender preferences. ${ }^{[9]}$

\section{Conclusions}

Despite the increasing number of male nurses in Canada, female nurses were generally perceived to be better suited to the nursing profession by most of the male patients interviewed. There is a need for educational institutions to determine new ways to teach male nursing students to be caring, nurturing, and detail-oriented. This study provides a starting point for a dialogue regarding how gender is perceived by male patients. This can be used to inform nursing education and practice and give direction to future research to help change the ways that male nurses practice. It also emphasizes that whether nurses are male or female, having a caring approach is important to patients, as well as possessing other characteristics participants considered as 'ideal'. 


\section{ACKNOWLEDGeMents}

The authors would like to sincerely thank the men who participated in this study, as well as Stephanie Morrison and Kitty Yin who assisted with manuscript preparation. This research did not receive any specific grant from funding agencies in the public, commercial, or not-for-profit sectors.

\section{CONFlicts OF InTEREST Disclosure}

The authors declare that there is no conflict of interest.

\section{REFERENCES}

[1] Tollison AC. Stereotype threat in male nurse-patient interactions. Journal of Nursing Education. 2018; 57(10): 614-6. PMid:30277547 https ://doi.org/10.3928/01484834-20180921-08

[2] Canadian Nurses Association. Code of ethics for registered nurses. 2017. Available from: https://www.cna-aiic.ca/en/search \#q=Code\%20 of\%20Ethics\&f : cna-website-facet=[cna]

[3] Canadian Nurses Association. Registered nurses profile (including Nurse Practitioners), Canada. 2017. Available from: https://www.cna-aiic.ca/en/nursing-practice/the-p ractice-of-nursing/health-human-resources/nursing - statistics/canada\#sthash.tLN8y8yD.dpuf

[4] Amir H, Tibi Y, Groutz A, et al. Unpredicted gender preference of obstetricians and gynecologists by Muslim Israeli-Arab women. Patient Education \& Counseling. 2012; 86(2): 259-263. PMid:21680130 https://doi.org/10.1016/j.pec.2011.05.016

[5] Kerssens J, Bensing J, Andela M. Patient preference for genders of health professionals. Social Science \& Medicine. 1997; 44(10): 15311540. https://doi.org/10.1016/S0277-9536(96)00272-9

[6] Lodge N, Mallett J, Blake P, et al. A study to ascertain gynaecological patients' perceived levels of embarrassment with physical and psychological care given by female and male nurses. Journal of Advanced Nursing. 1997; 25(5): 893-907. https://doi.org/10 .1046/j.1365-2648.1997.1997025893.x

[7] Adeyemi-Adelanwa O, Barton-Gooden A, Dawkins P, et al. Attitudes of patients towards being cared for by male nurses in a Jamaican hospital. Applied Nursing Research. 2016; 29: 140-143. PMid:26856505 https://doi.org/10.1016/j.apnr.2015.06.015
[8] Ahmad M, Alasad J. Patients' preferences for nurses' gender in Jordan. International Journal of Nursing Practice. 2007; 13(4): 237-242. PMid:17640245 https://doi.org/10.1111/j.1440-172X. 20 $07.00633 . \mathrm{x}$

[9] Chur-Hansen A. Preferences for female and male nurses: The role of age, gender, and previous experience-year 2000 compared with 1984. Journal of Advanced Nursing. 2002; 37(2): 192-198. https : //doi.org/10.1046/j.1365-2648.2002.02079.x

[10] Cudé G, Winfrey K. The hidden barrier: Gender bias, fact or fiction? Nursing for Women's Health. 2007; 11: 254265. PMid:17883772 https://doi.org/10.1111/j.1751-486X.2007.00165.x

[11] Anthony A. Tear down the barriers of gender bias. Men in Nursing. 2006; 1(4): 43-49. https://doi.org/10.1097/01244664-200 608000-00014

[12] Polit DF, Beck CT. Nursing research: Generating and assessing evidence for nursing practice. Wolters Kluwer. 2017.

[13] Bussey K, Bandura A. Social cognitive theory of gender development and differentiation. Psychological Review. 1999; 106(4): 676-713. https://doi.org/10.1037/0033-295X.106.4.676

[14] Rosenthal TL, Zimmerman BJ. Social learning and cognition. Academic Press; 1978.

[15] Hildebrandt DE, Feldman SE, Ditrichs RA. Rules, models, and selfreinforcement in children. Journal of Personal and Social Psychology. 1973; 25: 1-5. https ://doi.org/10.1037/h0034249

[16] Satu E, Helvi K. The qualitative content analysis process. Journal of Advanced Nursing. 2007; 62(1): 107-115. PMid:18352969 https ://doi .org/10.1111/j.1365-2648.2007.04569.x 